Trends in prolonged sitting time among European adults: 27 country analysis

Karen Milton ${ }^{12^{*}}$, Joanne Gale ${ }^{2}$, Emmanuel Stamatakis ${ }^{3}$, Adrian Bauman ${ }^{2}$

1 British Heart Foundation Centre on Population Approaches for Non-Communicable Disease Prevention, Nuffield Department of Population Health, University of Oxford, New Richards Building, Old Road Campus, Headington, Oxford, OX3 7LF, England

2 Prevention research Collaboration, School of Public Health, University of Sydney, Charles Perkins Centre, University of Sydney, Camperdown, NSW 2050, Australia

3 Exercise and Sport Sciences, Faculty of Health Sciences, University of Sydney, Charles Perkins Centre, University of Sydney, Camperdown, NSW 2050, Australia

*Corresponding author

Corresponding author contact details:

British Heart Foundation Centre on Population Approaches for Non-Communicable Disease Prevention

Nuffield Department of Population Health

University of Oxford

New Richards Building

Old Road Campus

Headington

Oxford

OX3 7LF

England

karen.milton@dph.ox.ac.uk

Tel: +44 (0)1865 289474

Co-authors email addresses:

joanne.gale@sydney.edu.au

emmanuel.stamatakis@sydney.edu.au

adrian.bauman@sydney.edu.au 


\section{Trends in prolonged sitting time among European adults: 27 country analysis}

Objective: To examine trends in adult sitting time across 27 European countries.

Method: Data were from the Eurobarometer surveys collected in 2002, 2005, and 2013. Sitting time data were used to categorise respondents into 'low' (0 to $4 \mathrm{~h} 30 \mathrm{mins}$ ), 'middle' (4h31 to 7h30mins), and 'high' levels of sitting (>7h30mins). We modelled the likelihood of being in the high sitting group within a given country and overall across the three time points, controlling for age, gender, education, employment status, and physical activity. Results: In total 17 countries had sitting data at all three time points; among these countries the prevalence of 'high sitting' decreased steadily from $23.1 \%(95 \% \mathrm{Cl}=22.2-24.1)$ in 2002 to $21.8 \%(95 \% \mathrm{Cl}=20.8-22.8)$ in 2005 , and $17.8 \%(95 \% \mathrm{Cl}=16.9-18.7)$ in 2013 . A further 10 countries had data only over the latter two time points; among these countries the prevalence of high sitting decreased from $27.7 \%(95 \% \mathrm{Cl}=26.0-29.4)$ in 2005 to $19.0 \%$ $(95 \% \mathrm{Cl}=17.6-20.5)$ in 2013.

Conclusion: Time spent in sedentary behaviour may not be increasing in the European region, and prolonged sitting may, in fact, be decreasing. This finding has important implications for the sedentary behaviour debate and the policy response.

Keywords: Sedentary behaviour, sitting time, trends, Europe, Eurobarometer

\section{Highlights}

- The paper examines trends in sedentary behaviour in the European region

- The results confirm that European adults spend large amounts of time sitting

- Overall sitting time does not appear to be increasing in the European region

- In no country does there appear to be a consistent trend towards more sitting 


\section{Introduction}

It has long been established that participation in moderate to vigorous physical activity for at least 150 minutes per week is associated with improved population health, and a reduced risk of developing a wide range of non-communicable diseases (NCDs) (Physical Activity Guidelines Advisory Committee, 2008; World Health Organization, 2010). Physical inactivity (failure to meet recommended physical activity levels) has been identified as the fourth leading risk factor for global mortality (World Health Organization, 2009) and is estimated to account for $9 \%$ of premature deaths (Lee et al., 2012).

'Sedentary behaviour' has also emerged as a topical issue in public health. Sedentary behaviour is defined as 'any waking behaviour characterized by an energy low expenditure while in a sitting or reclining posture' (Sedentary Behaviour Research Network, 2012). Because sedentary behaviour refers to time spent sitting/lying, it is not the same as a lack of physical activity (Owen, Healy, Matthews, \& Dunstan, 2010). Individuals can meet or exceed the public health guidelines for physical activity but still spend a considerable amount of time in sedentary behaviours (Edwardson et al., 2012; Sugiyama, Healy, Dunstan, Salmon, \& Owen, 2008). The most common form of sedentary behaviour is 'sitting', for example while travelling by car, train or bus, at school/work, and watching television.

Epidemiological studies suggest that time spent in sedentary behaviours may be associated with increased risk of all-cause mortality, cardiovascular mortality and cardiovascular diseases, poor cardio-metabolic biomarker profiles, and increased risk of diabetes (Chau et al. 2013; Katzmarzyk et al. 2009; Bauman et al. 2013; Wilmot et al. 2012); although several studies have shown null associations between accelerometry based sedentary behaviour and cardio-metabolic outcomes (Stamatakis, Davis, Stathi, \& Hamer, 2012; Stamatakis, Hamer, Tiling, \& Lawlor, 2012). In addition, some recent evidence suggests the observed risks of sedentary behaviour may not be independent of total physical activity levels (Maher, Olds, Mire, \& Katzmarzyk, 2014).

Over the past 50 years, increasing use of computers at work, labour saving devices in the home, and building and transportation practices that require driving for most trips, have led 
to reductions in physical activity levels globally (Brownson, Boehmer, \& Luke, 2005; Knuth \& Hallal, 2009; Kohl III et al., 2012; Sallis et al., 2006). It is assumed that the reductions in physical activity are accompanied by concomitant increases in sedentary behaviour (Owen, Sparling, Healy, Dunstan, \& Matthews, 2010; Thorp, Owen, Neuhaus, \& Dunstan, 2011). Interest in sedentary behaviour has grown exponentially in public health and the issue has pervaded the scientific literature and the media. For example, in 2014 alone there were over 340 scientific papers published with 'sedentary' in the title (Scopus, October 2014) and the issue has appeared in many newspapers worldwide with headlines such as 'Sitting is the new smoking' and 'Sitting down is KILLING you!' (Berry, 2013; Levine, 2014). There has also been increasing mention of the need for sedentary behaviour reduction in national physical activity policy recommendations, for example in Australia, Canada, Finland and Switzerland.

Although it is recognised that adults in Western countries spend large amounts of time engaged in sedentary behaviours (Matthews et al., 2008; The Information Centre for Health and Social Care, 2009), to date there has been limited population surveillance data to determine whether time spent in sedentary behaviours is actually increasing. Gaining a better understanding of trends in sedentary behaviour could inform public health policy and the need for action. The aim of this study was to examine trends in sitting time across 27 European countries between 2002 and 2013 using Eurobarometer data, a standardised long-term pan-European survey covering a wide range of social, economic, and health issues.

\section{Methods}

\section{Recruitment and Participants}

The Eurobarometer, established in 1973, is a set of cross-national serial surveys conducted on behalf of the European Commission (European Commission, 2014). Since 1990 (EB34), the survey has consisted of two elements. The first is the 'Standard EB' which contains the core set of questions which are similar in every survey. The second part is the 'Special EB' which is a supplementary optional survey on specific topic areas. 
The 2002 Special EB (EB58.2) included physical activity and sitting time, using the International Physical Activity Questionnaire (IPAQ; Craig et al., 2003). The IPAQ provides data on total time spent in vigorous intensity activity, moderate intensity activity, and walking. In addition, it includes a validated single-item question on sitting (Rosenberg, Bull, Marshall, Sallis, \& Bauman, 2008). These questions were also asked in EB64.3 conducted in 2005 and EB80.2 conducted in 2013, providing comparable information for our research question, to examine trend data on adult sitting time in Europe.

Eurobarometer surveys cover the population, aged 15 years and over, of the respective nationalities of the EU member states. For each survey independent samples were drawn from each member state using a multi-stage, random (probability) sampling design. The number of sampling points was drawn with probability proportional to population size (for a total coverage of the country) and to population density. The sampling points represented the whole territory of member states, and the distribution of the populations in terms of metropolitan, urban, and rural areas. Sample sizes within countries ranged from 302 in Northern Ireland in 2002 to 1039 in West Germany in 2013. The total participant numbers in 2002, 2005, and 2013 were 16 230, 29 193, and 27919 respectively. All interviews were face-to-face in the respondent's home and in the appropriate national language. More information on the Eurobarometer series can be found at http://www.gesis.org/en/eurobarometer/survey-series/standard-special-eb/.

\section{Measures and Data Management}

The IPAQ provided data on total physical activity (walking, moderate, and vigorous intensity activity) in the last seven days and total sitting time on a typical week day. In the 2002 and 2005 surveys, participants were asked to estimate their usual weekday sitting time using an open-ended response scale; however, for the 2013 survey participants were given a choice of 11 categorical response options, ranging from ' $\leq 60 \mathrm{mins}^{\prime}$ to '>8h30mins'. For the purposes of this study, sitting time data over all three time points were used to categorise respondents into 'low' ( 0 to $4 \mathrm{~h} 30 \mathrm{mins})$, 'middle' (4h31 to $7 \mathrm{~h} 30 \mathrm{mins})$, and 'high' sitting groups (>7h30mins). The threshold to define high sitting was based on the cut point for increased risk obtained from a meta-analysis of the dose-response relationship between total sitting time and all-cause mortality (Chau et al., 2013). Similarly to estimated sitting 
time, in the 2002 and 2005 surveys, participants were asked to estimate the amount of time they spent doing physical activity (walking, moderate and vigorous intensity) using an open ended response scale; however this was changed to a categorical response scale for the 2013 survey. Since the 2013 data contained only categorical data of minutes of physical activity per day, it was not possible to calculate total physical activity using the IPAQ scoring system. Instead, total physical activity was calculated by summing the total number of days of walking, moderate, and vigorous intensity activity, and then classifying participants according to quartiles within each survey year. To control for the influences of sociodemographic factors on sitting time, data on age group (15-24yrs, 25-34yrs, 35-44yrs, 45$54 y r s, 55-64 y r s$ and 65yrs and above), gender (male or female), education level (18 years and less or 19 years and more), and employment status (student, employed, or unemployed/retired) from each Eurobarometer survey were used in the analysis. The frequency of participants in each physical activity and sitting time category in each survey year are shown in Supplemental Table 1.

\section{Statistical Analysis}

Descriptive statistics were calculated to show frequencies of each sample within each sitting category (low, middle, and high) for each country across each survey year. Multiple logistic regression was used to model the probability of being in the high sitting group within a given country and overall across the three survey years. These models were controlled for age group, gender, education level, employment status, and physical activity quartile. Post stratification weights were applied across all analyses, where the data for each participant was weighted using population within country and country population within the member states. Post stratification weights are available in each Eurobarometer data set and are calibrated according to either the entire European community or particular groupings. More information can be found at http://www.gesis.org/en/eurobarometer/surveyseries/standard-special-eb/weighting-overview/.

\section{Results}

In total 17 countries/regions had valid sitting data in all three time points $(2002,2005,2013)$ and a further 10 countries/regions had valid data in the latter two time points only (2005, 
2013). Table 1 presents the weighted mean, median, and interquartile range of sitting time as well as the distribution of the key characteristics of the sample (age, gender, education, employment status) in each of the three Eurobarometer time points. Supplemental Table 2 presents the weighted mean, median, and interquartile range of sitting time by country and time point.

\section{Temporal trends 2002-2013 across 17 countries/regions}

\section{Temporal trends in overall distribution of sitting}

Figure 1 presents the weighted frequency distribution of low ( 0 to $4 \mathrm{~h} 30 \mathrm{mins}$ ), middle (4h31 to $7 \mathrm{~h} 30 \mathrm{mins}$ ), and high ( $>7 \mathrm{~h} 30 \mathrm{mins})$ sitting in the pooled sample of countries that had data in all three time points. The low sitting group remained stable, while the middle sitting group increased; there was a slight increase in the middle sitting group between 2002 and 2005, and a more pronounced increase between 2005 and 2013. The prevalence of high sitting decreased steadily from $23.1 \%(95 \% \mathrm{Cl}=22.2-24.1)$ in 2002 to $21.8 \%(95 \% \mathrm{Cl}=20.8-$ $22.8)$ in 2005 , and $17.8 \%(95 \% \mathrm{Cl}=16.9-18.7)$ in 2013 . Supplemental Figure 1 presents the country specific prevalence trends in the three sitting time categories across the three time points, and shows mostly the same pattern, with downward trends in the high sitting group in 10 out of 17 countries.

\section{Temporal trends in high sitting time (>7h30mins)}

Figure 2 shows the weighted country-specific temporal trends in high sitting (>7h30mins) for each of the 17 counties/regions with complete data. In some countries the proportion of the population in the high sitting category has remained relatively stable over time; however, more commonly there is a trend towards reductions in high sitting across the three survey time points. In no country does there appear to be a trend towards greater prevalence of high sitting. Supplemental Table 3 presents the multivariable-adjusted odds for high sitting time for each country/region separately and all 17 countries pooled. The adjusted odds of high sitting decreased gradually over time. Compared to 2002, the high sitting time odds ratio was $0.87(95 \% \mathrm{Cl}=0.80-0.95)$ in 2005 and $0.69(95 \% \mathrm{Cl}=0.63-0.76)$ in 2013. In comparison to 2002, lower odds for high sitting in 2013 were evident in 9 out of 17 countries/regions (Belgium, West Germany, East Germany, Italy, Denmark, Ireland, 
Greece, Spain, and Portugal). Figures 3 A and 3B present the multivariable-adjusted odds ratios and 95\% Cls for high sitting in 2013 compared to 2002, and in 2005 compared to 2002, respectively. Figure 3A shows the tendency towards lower odds for high sitting in 2013 compared to 2002; Figure 3B shows that this trend towards a reduction in high sitting was already present (although non-significant in most cases) in 2005.

\section{Changes between 2005 and 2013 across 10 countries/regions}

\section{Changes in overall distribution of sitting}

Supplemental Figure 2 presents the weighted frequency distribution of low ( 0 to 4 h 30 mins), middle (4h31 to $7 \mathrm{~h} 30 \mathrm{mins}$ ), and high ( $>7 \mathrm{~h} 30 \mathrm{mins}$ ) sitting in the pooled sample of countries/regions that had data in 2005 and 2013 only. There was an increase in the percentage of the pooled 10 country sample classified in the low sitting group, from $45.8 \%$ $(95 \% \mathrm{Cl}=44.0-47.7)$ to $49.4 \%(95 \% \mathrm{Cl}=47.5-51.2)$, and in the middle sitting group, from $26.4 \%(95 \% \mathrm{Cl}=24.8-28.1)$ to $31.6 \%(95 \% \mathrm{Cl}=29.9-33.3)$. The prevalence of high sitting decreased from $27.7 \%(95 \% \mathrm{Cl}=26.0-29.4)$ in 2005 to $19.0 \%(95 \% \mathrm{Cl}=17.6-20.5)$ in 2013 . Supplemental Figure 3 presents the country-specific changes in the three sitting time categories between 2005 and 2013. Consistent with the pooled analysis of the 10 countries, reductions in high sitting prevalence was evident across most individual countries.

\section{Overall changes between 2005 and 2013 in all 27 countries/regions}

\section{Changes in overall distribution of sitting}

Supplemental Figure 4 presents the weighted frequency distribution of low ( 0 to 4 h30mins), middle (4h31 to 7h30mins), and high (>7h30mins) sitting in 2005 and 2013 in the pooled sample of all 27 countries/regions. The proportion of the sample in the low sitting group remained relatively stable over time, with $48.0 \%(95 \% \mathrm{Cl}=47.0-49.0)$ in this category in 2002 and $47.4 \%$ (46.4 - 48.4) classified in the low sitting group in 2013. There was an increase between 2005 and 2013 in the percentage of the sample in the middle sitting group, from $29.2 \%(95 \% \mathrm{Cl}=28.3-30.2)$ to $34.6 \%(95 \% \mathrm{Cl}=33.7-35.6)$, and a decrease in the percentage of the sample in the high sitting group, from $22.8 \%(95 \% \mathrm{Cl}=22.0-23.6)$ to $18.0 \%(95 \% \mathrm{Cl}=17.2-18.8)$. 
Changes in high sitting time (>7h30mins)

When all 27 countries were pooled, the odds of high sitting were lower in 2013 compared to $2005(\mathrm{OR}=0.79,95 \% \mathrm{Cl}=0.73-0.86)$. Figure 4 presents the country-specific multivariableadjusted odds ratios and 95\% Cls for high sitting in 2013 compared to 2005. Although there was a tendency for lower likelihood of high sitting in the majority of countries, the difference was statistically significant in 9 of the 27 countries/regions (Slovenia, Poland, Czech Republic, Cyrpus, Hungary, Spain, Greece, Netherlands and Belgium). The only countries where the likelihood of high sitting was higher in 2013 compared to 2005 were Austria and France.

\section{Discussion}

The Eurobarometer is the first cross-national study to provide trend data on sitting time among adults. This paper examined data from the Eurobarometer over three time points, to determine whether time spent in sedentary behaviours has changed in the European region.

The results confirm that European adults spend large amounts of time engaged in sedentary behaviours. Across all countries which were included in the analyses, the mean daily sitting time in minutes was 316.2, 312.0, and 291.9 in 2002, 2005, and 2013 respectively, and the median and interquartile range for all three surveys was around $300(180-420)$ minutes. These sitting time values are similar to what has been reported previously, both in Europe and elsewhere (Bauman et al., 2011; Bennie et al., 2013). For example, an earlier analysis of sitting time in Europe, using Eurobarometer data from 32 countries, reported a median sitting time value of 300 minutes with an interquartile range of 180 - 420 (Bennie et al., 2013), and an analysis of sitting time in 20 diverse countries (including both European and non-European countries) reported a median value of 300 minutes/day with an interquartile range of 180 - 480 minutes (Bauman et al., 2011).

Previous research has identified that each hour of daily sitting time is associated with a $2 \%$ increase in all-cause mortality risk, after taking the protective health effects of physical 
activity into account. However, when adults sit for 7 hours or more per day, the risk increases by $5 \%$ for each incremental hour in daily sitting time (Chau et al., 2013). Therefore, people who sit for more than 7 hours per day are at particularly high risk of the adverse health consequences of sedentary behaviour. For the current study we were restricted by the categorical response scale used in the Eurobarometer 80.2 (2013), and consequently we used a category of greater than 7h30mins to define 'high sitting time', as opposed to the previously identified threshold of 7 hours (Chau et al., 2013).

The analyses were undertaken in two parts; the first included countries/regions with data from all three time points $(2002,2005,2013)$. This grouping of 17 countries/regions are of particular interest, as the three time points provide more robust evidence on the pattern of change in sedentary behaviour over time. The current research found that across these three time points the overall proportion of participants in the low sitting category remained relatively stable; however the proportion in the middle category steadily increased, while the proportion in the high category steadily decreased. Although there were variations in the pattern of change between countries, in no country does there appear to be a consistent trend towards a greater prevalence of high sitting.

The second part of the analysis included the 10 countries/regions with data for the latter two time points only. Between 2005 and 2013, these countries demonstrated an increase in the proportion of participants in the low and middle sitting categories and a decrease in the high sitting category. The reduction in high sitting was particularly pronounced among these 10 countries. Across all 27 countries/regions, the results show an overall significant reduction in the proportion of participants in the most at risk (high sitting) group in 2013 in comparison to 2005. Although the sitting time question has remained consistent, the response scale differed between the 2005 and 2013 surveys, which may have confounded these results.

While several studies have documented trends towards lower overall physical activity levels (Brownson et al., 2005; Knuth \& Hallal, 2009; Kohl III et al., 2012; Sallis et al., 2006) and declines in occupational physical activity, for example in the USA and in Norway (Church et al., 2011; Graff-Iversen, Skurtveit, Sørensen, \& Nybø, 2001), particularly over the past 50 
years, studies have not assessed whether there has been an overall change in total sitting time. While physical activity surveillance has a relatively long history, sedentary behaviour surveillance is a relatively new development. Thus, it has previously been assumed that as physical activity decreases, sedentary behaviour increases, although to date there has been limited longitudinal trend data on sedentary behaviour to support this supposition.

This is one of the first studies to report trends in sedentary behaviour over time using a standardised long-term survey. The results suggest that, contrary to popular belief, sitting time may not be increasing in the European region. Although little change was observed in the proportion of people in the low and middle sitting categories, there appears to have been a decline over time in the proportion of people who sit for more than 7h30mins per day. This is an important finding for public health policy, given the emerging risks associated with prolonged sitting.

Incorporating serial questions on sedentary behaviour into other surveillance systems is needed to corroborate or refute these Eurobarometer observations. In addition, further research is needed to explore the factors which may be contributing to the reported reduction in sitting time across the European region. These findings point to the need for further investment into understanding the prevalence and trends in sedentary behaviour, as well as the health consequences of prolonged sitting, to inform an appropriate and proportional policy response to the issue.

Several limitations of this research should be acknowledged. Firstly, sitting data from the Eurobarometer are from a self-report survey (IPAQ). Although the IPAQ is a validated tool, with the question on sitting time demonstrating better validity coefficients than the physical activity questions (Craig et al., 2003; Rosenberg et al., 2008), all self-report tools are subject to social desirability and recall biases (Shephard, 2003). Previous research suggests that participants are likely to under-estimate the time that they spend sitting when completing self-report surveys (Clemes, David, Zhao, Han, \& Brown, 2012), but there is no information on whether this bias is differential over time. In addition, for the 2013 Eurobarometer survey the response scale for the sitting time question was changed from an open ended to 
a categorical response scale. It is possible that the revised response scale influenced how respondents perceived and reported their sitting time.

It is likely that increased media attention on sedentary behaviour has led to increased public awareness of the issue. This media attention may have led to reductions in sedentary behaviour; it is also possible however, that increased awareness has simply led people to under-report their sedentary time, rather than influencing their behaviour. This supports the need for objective population assessment of sedentary behaviour. Finally, the Eurobarometer uses population-based samples, and not true representative sampling; however, the sampling methods (and therefore selection bias) have remained consistent over-time, and thus the Eurobarometer provides a useful tool for comparing trends, despite not being truly representative at the country level.

\section{Conclusion}

The current study used data from the Eurobarometer survey at three time points over the past 15 years, to examine trends in adult sitting time in the European region. The results show that, contrary to recent reports (Owen, Sparling, et al., 2010; Thorp et al., 2011), time spent in sedentary behaviour may not be increasing in the European region, and prolonged sitting may, in fact, be decreasing. This finding emphasises the importance of collecting comparable cross-country data, monitored over time. It also emphasises the need to better understand the prevalence, trends, and health consequences of sedentary behaviour to inform the scale of the response afforded by communities, the media and policymakers.

\section{Conflict of interest statement:}

The authors declare that they have no conflicts of interest.

\section{Acknowledgement:}

Eurobarometer data provided by the GESIS Social Science Data archive, at the Leibniz Institute for the Social Sciences, Germany. 


\section{References}

Bauman, A., Ainsworth, B., Sallis, J., Hagströmer, M., Craig, C., Bull, F., ... Group, I. (2011). The descriptive epidemiology of sitting - A 20-country comparison using the International Physical Activity Questionnaire (IPAQ). American Journal of Preventive Medicine, 41(2), 228-235.

Bauman, A., Chau, J., Ding, D., \& Bennie, J. (2013). Too much sitting and cardio-metabolic risk: An update of epidemiological evidence. Current Cardiovascular Risk Reports, DOI 10.1007/s12170-013-0316-y.

Bennie, J., Chau, J., van der Ploeg, H., Stamatakis, E., Do, A., \& Bauman, A. (2013). The prevalence and correlates of sitting in European adults - a comparison of 32 Eurobarometer-participating countries. International Journal of Behavioural Nutrition and Physical Activity, 10, 107.

Berry, S. (2013, May 30). Sitting is the new smoking. The Sydney Morning Herald. Retrieved from http://www.smh.com.au/lifestyle/life/sitting-is-the-new-smoking-201305292nca0.html

Brownson, R., Boehmer, T., \& Luke, D. (2005). Declining rates of physical activity in the United States: what are the contributors? Annual Review of Public Health, 26, 421-443.

Chau, J., Grunseit, A., Chey, T., Stamatakis, E., Brown, W., Matthews, C., ... van der Ploeg, H. (2013). Daily sitting time and all-cause mortality: A meta-analysis. PLoS One, 8(11), e80000.

Church, T., Thomas, D., Tudor-Locke, C., Katzmarzyk, P., Earnest, C., Rodarte, R., ... Bouchard, C. (2011). Trends over 5 decades in U.S. occupation-related physical activity and their associations with obesity. PLoS One, 6(5), e19657. doi:10.1371/journal.pone.0019657.

Clemes, S., David, B., Zhao, Y., Han, X., \& Brown, W. (2012). Validity of two self-report measures of sitting time. Journal of Physical Activity and Health, 9(4), 533-539.

Craig, C., Marshall, A., Sjöström, M., Bauman, A., Booth, M., Ainsworth, B., ... Oja, P. (2003). International physical activity questionnaire: 12-country reliability and validity. Medicine and Science in Sports and Exercise, 35(8), 1381-1395.

Edwardson, C., Gorely, T., Davies, M., Gray, L., Khunti, K., Wilmot, E., ... Biddle, S. (2012). Association of sedentary behaviour with metabolic syndrome: a meta-analysis. PLOS One, 7(4), e34916. doi: 10.1371/journal.pone.0034916.

European Commission. (2014). Public opinion. Retrieved from http://ec.europa.eu/public_opinion/index_en.htm 
Graff-Iversen, S., Skurtveit, S., Sørensen, M., \& Nybø, A. (2001). Occupational physical activity and overweight: what are the associations? Tidsskr Nor Lægeforen, 121, 25792583.

Hallal, P., Andersen, L., Bull, F., Guthold, R., Haskell, W., \& Ekelund, U. (2012). Global physical activity levels: Surveillance progress, pitfalls, and prospects. The Lancet, 380, 247-257.

Katzmarzyk, P., Church, T., Craig, C., \& Bouchard, C. (2009). Sitting time and mortality from all causes, cardiovascular disease, and cancer. Medicine \& Science in Sports \& Exercise, 41(5), 998-1005.

Knuth, A., \& Hallal, P. (2009). Temporal trends in physical activity: a systematic review. Journal of Physical Activity and Health, 6, 548-559.

Kohl III, H., Craig, C., Lambert, E., Inoue, S., Alkandari, J., Leetongin, G., ... for the Lancet Physical Activity Series Working Group. (2012). The pandemic of physical inactivity: Global action for public health. Lancet, 380, 294-305.

Lee, I., Shiroma, E., Lobelo, F., Puska, P., Blair, S., \& Katzmarzyk, P. (2012). Effects of physical inactivity on major non-communicable diseases worldwide: An analysis of burden of disease and life expectancy. The Lancet, 380, 219-229.

Levine, J. (2014, July 26). Sitting down is KILLING you! Daily Mail Australia. Retrieved from http://www.dailymail.co.uk/news/article-2706317/Sitting-KILLING-Heart-diseaseobesity-depression-crumbling-bones-terrifying-new-book-doctor-reveals-linked-hoursspend-chairs.html

Maher, C., Olds, T., Mire, E., \& Katzmarzyk, P. (2014). Reconsidering the Sedentary Behaviour Paradigm. PLoS One, 9(1), e86403. doi:doi:10.1371/ journal.pone.0086403

Matthews, C., Chen, K., Freedson, P., Buchowski, M., Beech, B., Pate, R., \& Troiano, R. (2008). Amount of time spent in sedentary behaviors in the United States, 2003-2004. American Journal of Epidemiology, 167(7), 875-881.

Owen, N., Healy, G., Matthews, C., \& Dunstan, D. (2010). Too much sitting: the population health science of sedentary behavior. Exercise and Sport Sciences Reviews, 38(3), 105113.

Owen, N., Sparling, P., Healy, G., Dunstan, D., \& Matthews, C. (2010). Sedentary behavior: Emerging evidence for a new health risk. Mayo Clinic Proceedings, 85(12), 1138-1141.

Physical Activity Guidelines Advisory Committee. (2008). Physical activity guidelines advisory committee report 2008. Washington, DC.

Rosenberg, D., Bull, F., Marshall, A., Sallis, J., \& Bauman, A. (2008). Assessment of sedentary behavior with the International Physical Activity Questionnaire. Journal of Physical Activity and Health, 5(Supplement 1), S30-S44. 
Sallis, J., Cervero, R., Ascher, W., Henderson, K., Kraft, M., \& Kerr, J. (2006). An ecological approach to creating active living communities. Annual Reviews of Public Health, 27, 297-322.

Sedentary Behaviour Research Network. (2012). Letter to the editor: standardized use of the terms "sedentary" and "sedentary behaviours." Applied Physiology, Nutrition, and Metabolism, 37(3), 540-542.

Shephard, R. (2003). Limits to the measurement of habbuitual physical activity by questionnaires. British Journal of Sports Medicine, 37, 197-206.

Stamatakis, E., Davis, M., Stathi, A., \& Hamer, M. (2012). Associations between multiple indicators of objectively-measured and self-reported sedentary behaviour and cardiometabolic risk in older adults. Preventive Medicine, 54, 82-87.

Stamatakis, E., Hamer, M., Tiling, K., \& Lawlor, D. (2012). Sedentary time in relation to cardio-metabolic risk factors: differential associations for self-report versus accelerometry in working age adults. International Journal of Epidemiology, 41(5), 1328 $-1337$.

Sugiyama, T., Healy, G., Dunstan, D., Salmon, J., \& Owen, N. (2008). Joint associations of multiple leisure-time sedentary behaviours and physical activity with obesity in Australian adults. International Journal of Behavioural Nutrition and Physical Activity, 5(35).

The Information Centre for Health and Social Care. (2009). Health Survey for England 2008. Volume 1. Physical activity and fitness. Leeds, UK.

Thorp, A., Owen, N., Neuhaus, M., \& Dunstan, D. (2011). Sedentray behaviors and subsequent health outcomes in adults: A systematic review of longitudinal studies. American Journal of Preventive Medicine, 41(2), 207-215.

Wilmot, E., Edwardson, C., Achana, F., Davies, M., Gorely, T., Gray, L., ... Biddle, S. (2012). Sedentary time in adults and the association with diabetes, cardiovascular disease and death: systematic review and meta-analysis. Diabetologia, 55(11), 2895-2905.

World Health Organization. (2009). Global health risks: Mortality and burden of disease attributable to selected major risks. Geneva.

World Health Organization. (2010). Global recommendations on physical activity for health. Geneva. 
Table 1: Summary statistics for key variables in Eurobarometer $58.2,64.3$ and 80.2 by year - weighted data for the 27 member states/regions included in the analysis

\begin{tabular}{|c|c|c|c|c|}
\hline Variable & & $\begin{array}{r}2002 \\
\text { (EB58.2) }\end{array}$ & 2005 (EB64.3) & 2013 (EB80.2) \\
\hline \multirow[t]{5}{*}{ Age } & $\mathrm{N}$ & 16230 & 24682 & 24878 \\
\hline & Mean (SD) & $44.8(18.2)$ & $45.5(16.9)$ & $47.0(17.4)$ \\
\hline & 25\% Quartile & 29.0 & 30.0 & 32.0 \\
\hline & Median & 43.0 & 44.0 & 46.0 \\
\hline & 75\% Quartile & 59.0 & 60.0 & 62.0 \\
\hline \multirow[t]{3}{*}{ Gender } & $\mathrm{N}$ & 16230 & 24682 & 24878 \\
\hline & $\%$ Male & 48.3 & 48.2 & 48.3 \\
\hline & $\%$ Female & 51.7 & 51.8 & 51.7 \\
\hline \multirow[t]{5}{*}{ Years of education } & $\mathrm{N}$ & 14619 & 22092 & 22949 \\
\hline & Mean (SD) & $17.5(4.8)$ & $18.6(7.2)$ & $19.0(6.8)$ \\
\hline & 25\% Quartile & 15.0 & 15.0 & 16.0 \\
\hline & Median & 17.0 & 18.0 & 18.0 \\
\hline & 75\% Quartile & 19.0 & 20.0 & 21.0 \\
\hline \multirow[t]{3}{*}{ Employment status (\%) } & Student & 9.7 & 10.0 & 8.8 \\
\hline & Employed & 50.4 & 51.1 & 50.0 \\
\hline & Unemployed or Retired & 39.9 & 39.0 & 41.2 \\
\hline \multirow[t]{5}{*}{ Sitting time $\left(\operatorname{mins} /\right.$ day) ${ }^{*}$} & $\mathrm{N}$ & 15247 & 23464 & 24313 \\
\hline & Mean (SD) & $\begin{array}{r}316.2 \\
(178.6)\end{array}$ & $312.0(165.7)$ & $291.9(137.5)$ \\
\hline & 25\% Quartile & 180.0 & 180.0 & 180.5 \\
\hline & Median & 300.0 & 300 & 300.5 \\
\hline & 75\% Quartile & 420.0 & 420.0 & 420.5 \\
\hline
\end{tabular}

*Since sitting time was collected as a categorical variable in 2013, all sitting time statistics are estimated 
Figure 1: Weighted frequency distributions for sitting time category for the pooled sample of 17 countries/regions with data in all three time points $\left(N_{\text {sum }}\right.$ of weights $\left.=47486\right)$

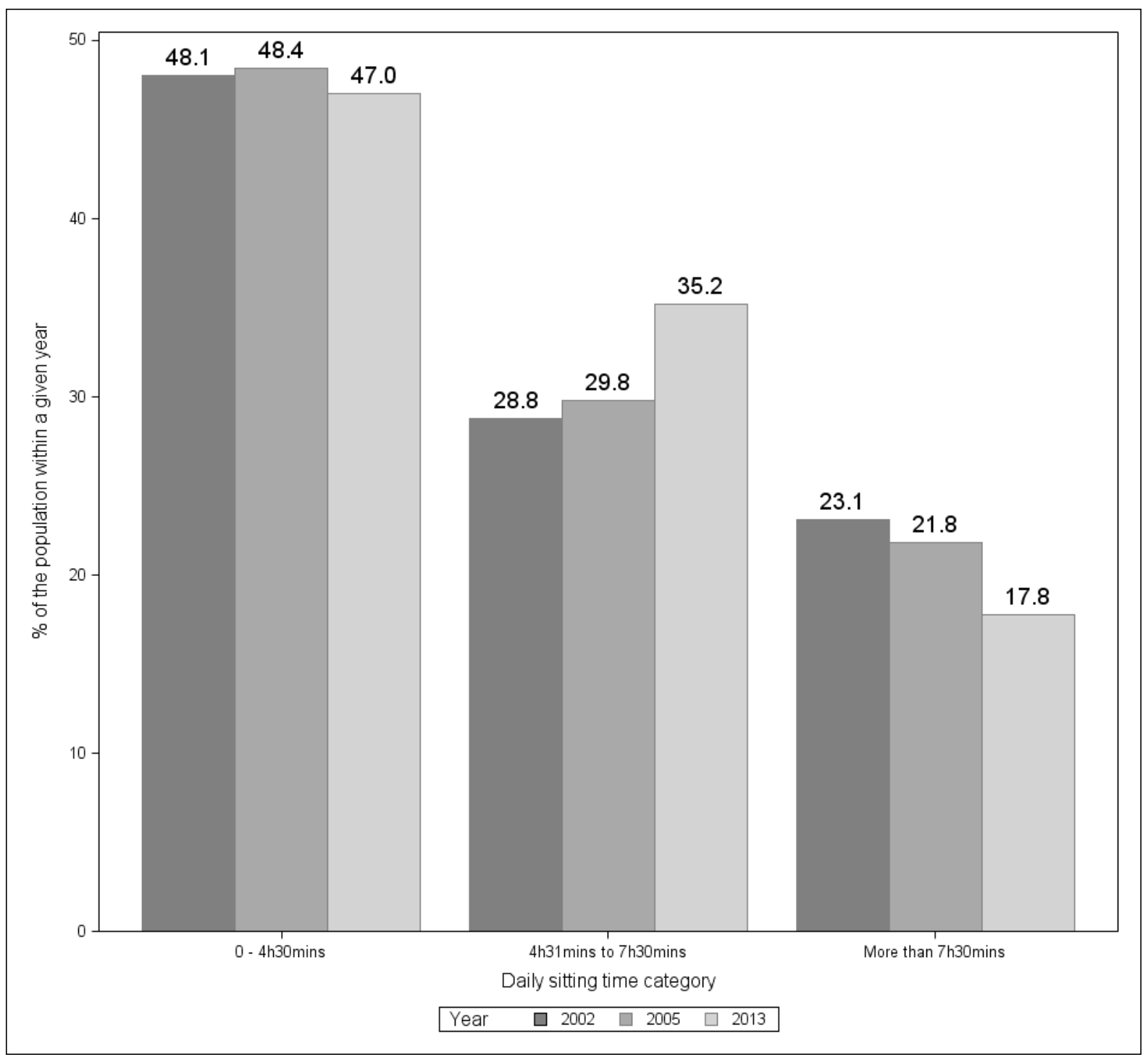


Figure 2: Weighted country-specific temporal trends in the prevalence of high sitting time (>7h30mins)

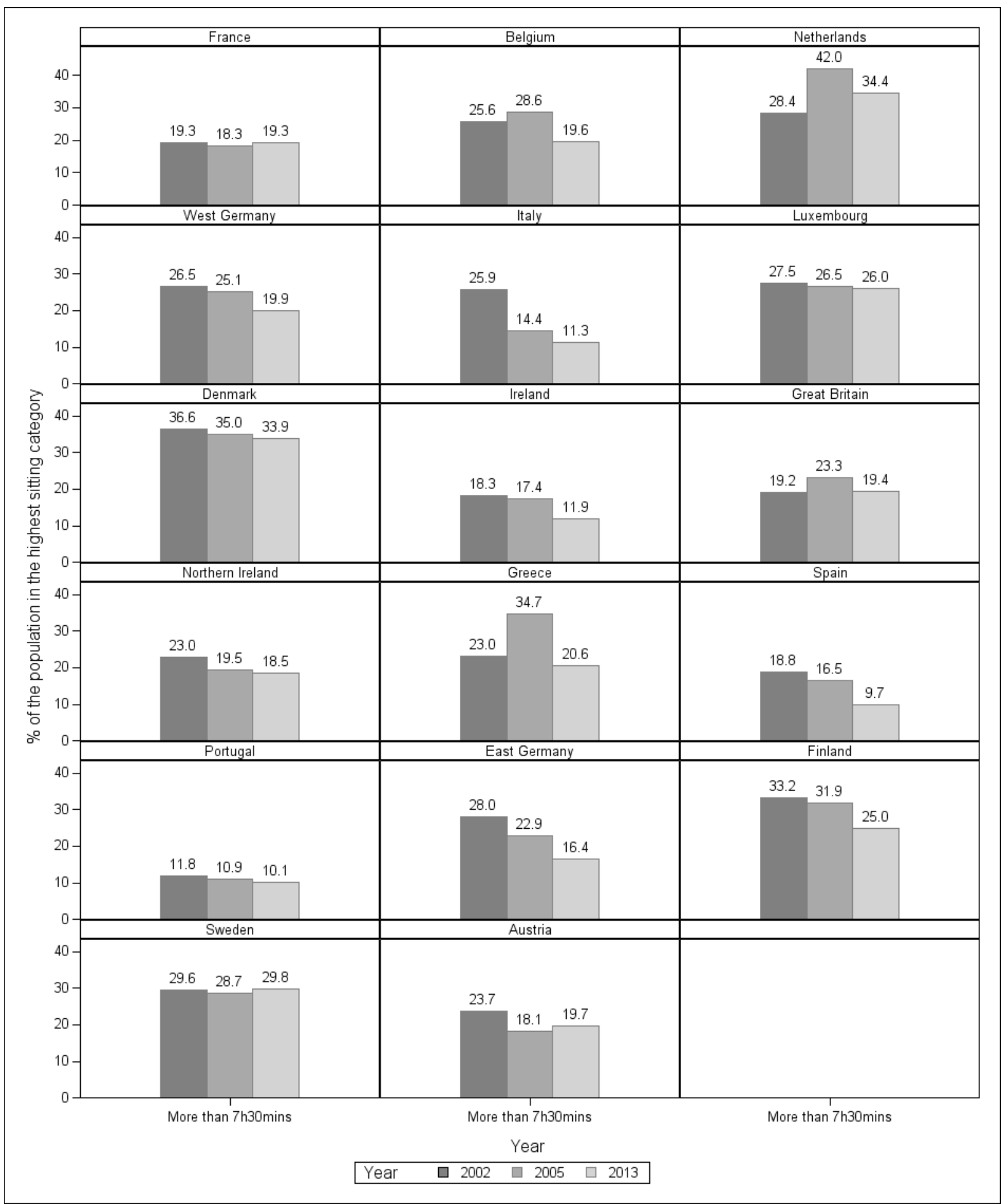


Figure 3: Country-specific adjusted odds ratios and $95 \% \mathrm{Cls}$ for high sitting time ( $>7 \mathrm{~h} 30 \mathrm{mins}$ ) in 2013 compared to 2002 (A); and in 2005 compared to 2002 (B) for the 17 countries/regions with data in all three time points

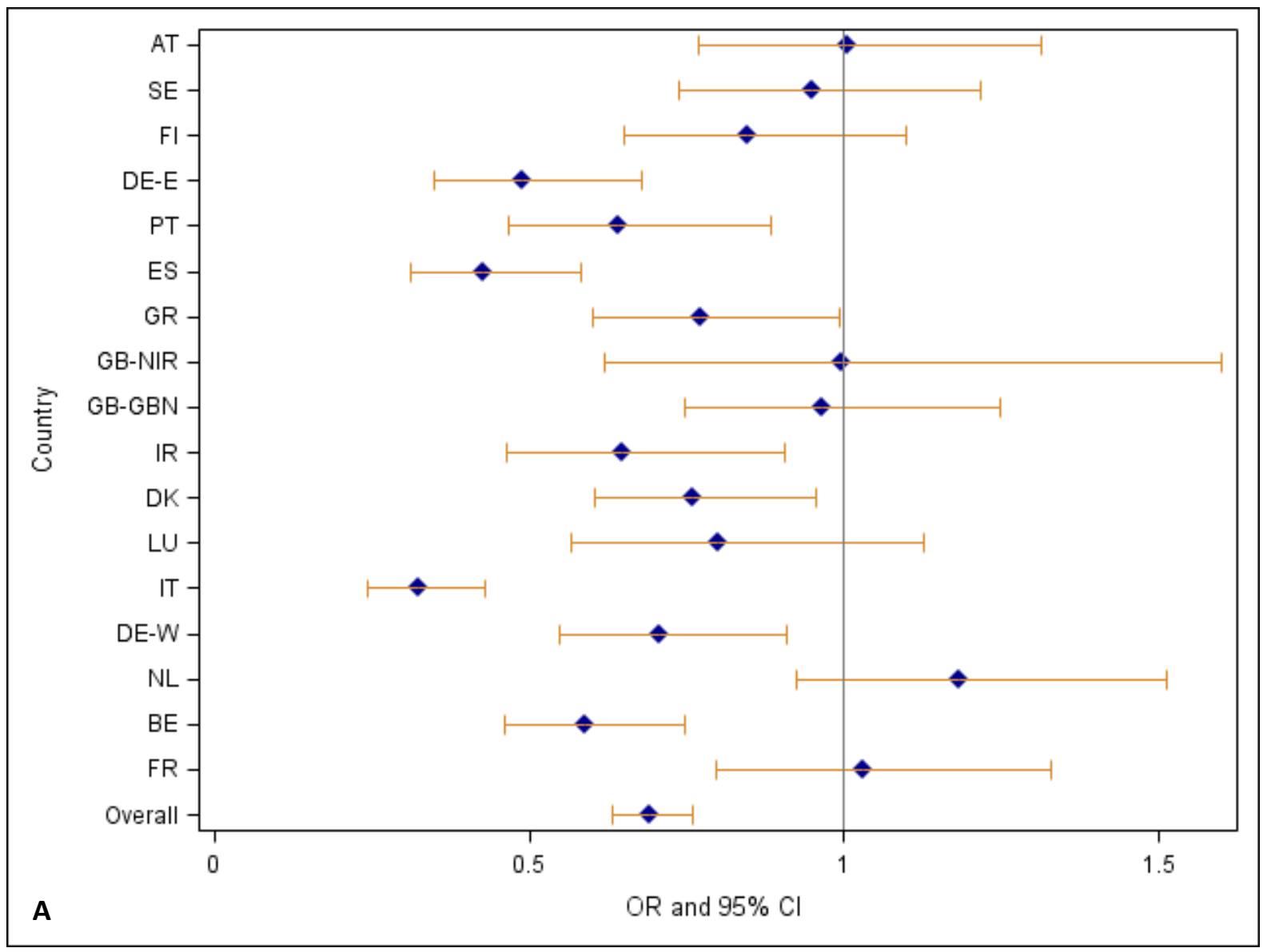




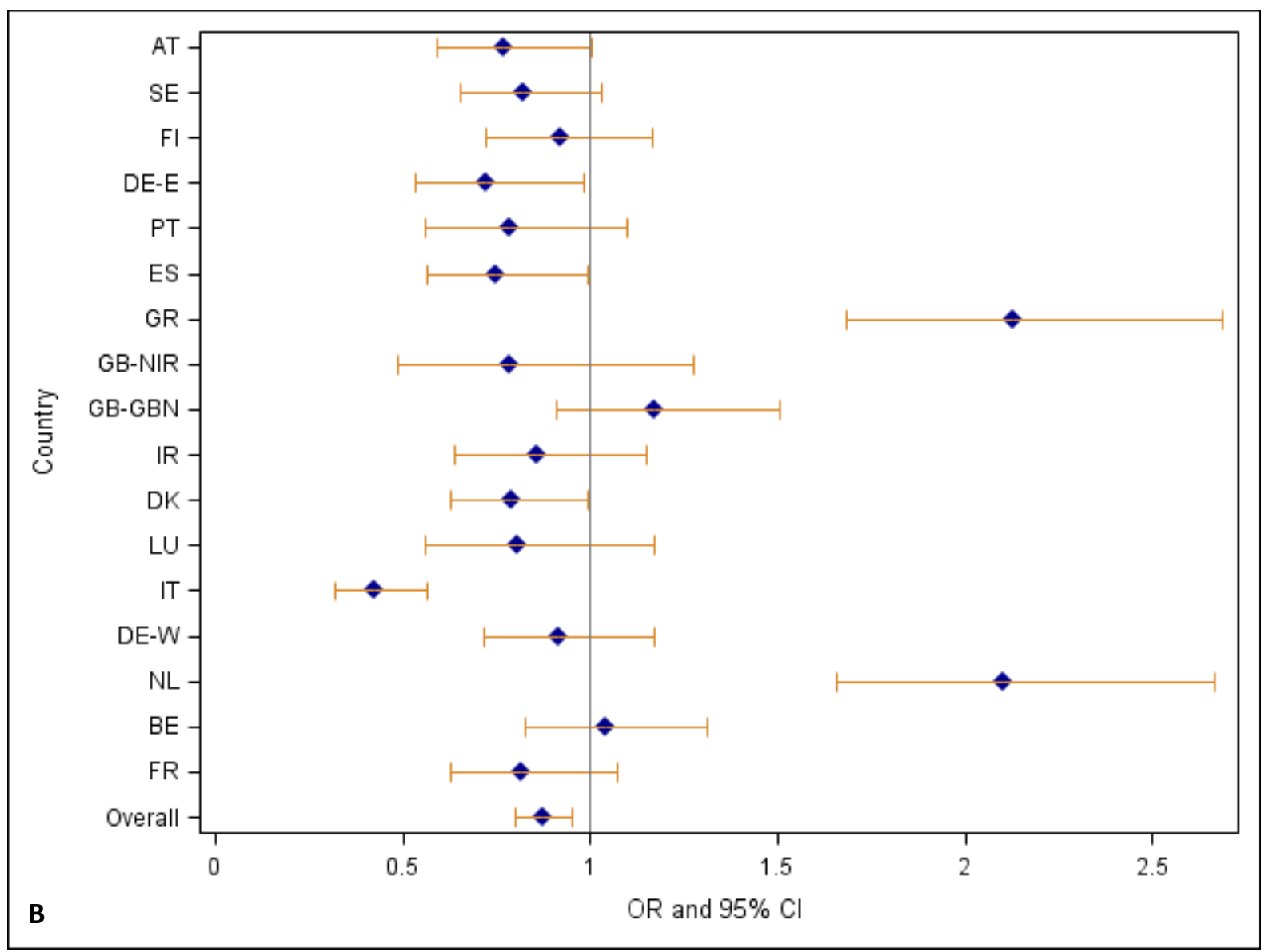

AT, Austria; SE, Sweden; FI, Finland; DE-E, East Germany; PT, Portugal; ES, Spain; GR, Greece; GB-NIR, Northern Ireland; GB-GBN, Great Britain; IR, Ireland; DK, Denmark; LU, Luxembourg; IT, Italy; DE-W, West Germany; NL, Netherlands; BE, Belgium; FR, France 
Figure 4: Country-specific adjusted odds ratios and $95 \% \mathrm{Cls}$ for high sitting time ( $>7 \mathrm{~h} 30 \mathrm{mins}$ ) in 2013 compared to 2005 in all 27 countries/regions

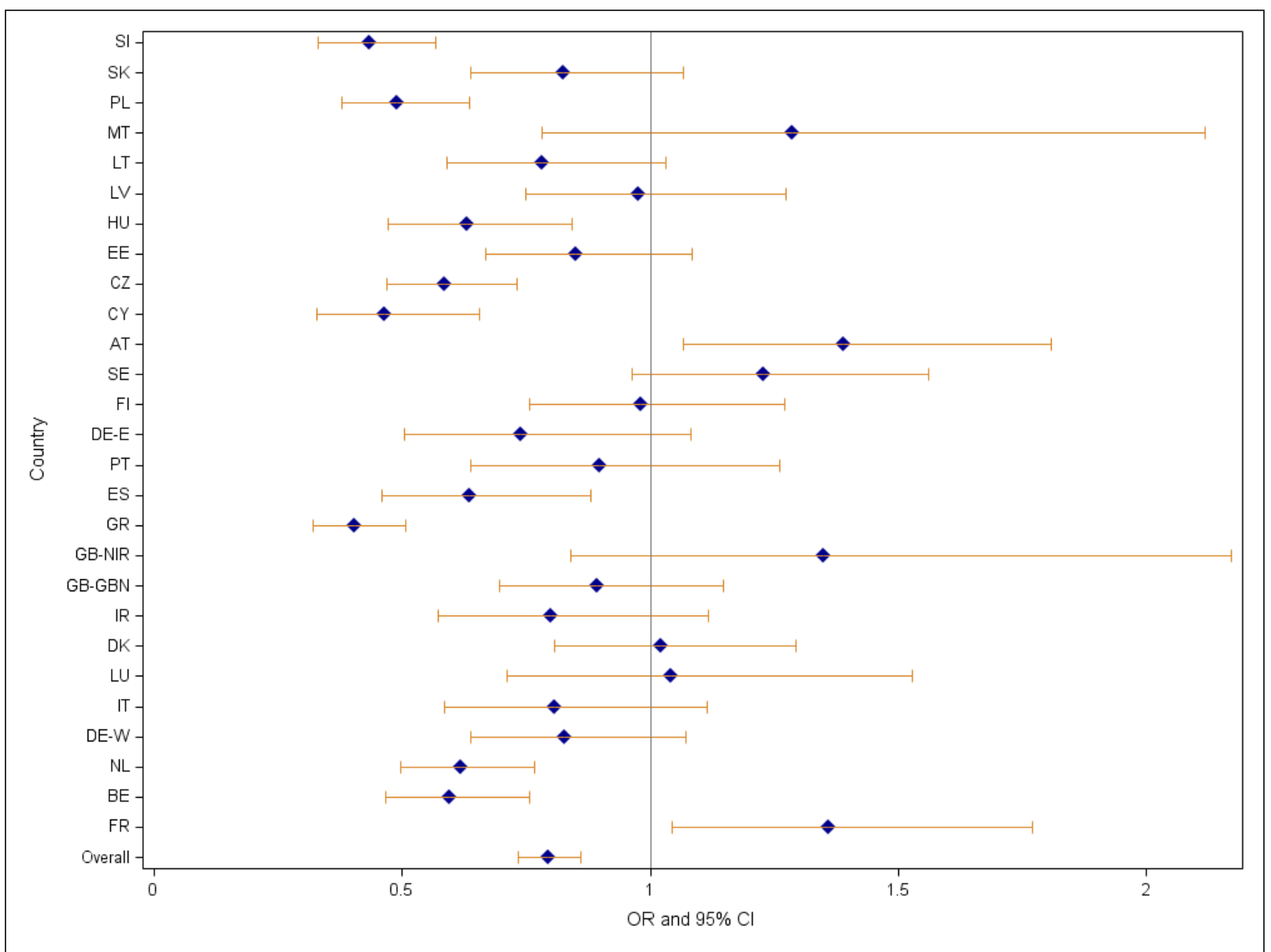

SI, Slovenia; SK, Slovakia (Slovak Republic); PL, Poland; MT, Malta; LT, Lithuania ; LV, Latvia; $\mathrm{HU}$, Hungary; EE, Estonia; CZ, Czech Republic ; CY, Cyprus; AT, Austria; SE, Sweden; FI, Finland; DE-E, East Germany; PT, Portugal; ES, Spain; GR, Greece; GB-NIR, Northern Ireland; GB-GBN, Great Britain; IR, Ireland; DK, Denmark; LU, Luxembourg; IT, Italy; DE-W, West Germany; NL, Netherlands; BE, Belgium; FR, France 
Supplemental Table 1: Percentage distributions of sitting time and physical activity categories at each time point - weighted data for the 27 countries/regions included in the analysis

\begin{tabular}{llrrr}
\hline Variable & Category & $\begin{array}{r}\mathbf{2 0 0 2} \\
\text { (EB58.2) }\end{array}$ & $\begin{array}{r}\mathbf{2 0 0 5} \\
\text { (EB64.3) }\end{array}$ & $\begin{array}{r}\mathbf{2 0 1 3} \\
\text { (EB80.2) }\end{array}$ \\
\hline Sitting time per day & Less than 1h & 5.5 & 6.0 & 4.4 \\
& 1h to 1h30mins & 1.4 & 1.7 & 5.1 \\
& 1h31mins to 2h30mins & 11.0 & 11.8 & 8.4 \\
& 2h31mins to 3h30mins & 14.8 & 14.2 & 14.2 \\
& 3h31mins to 4h30mins & 15.5 & 14.3 & 15.3 \\
& 4h31mins to 5h30mins & 12.1 & 12.7 & 14.6 \\
& 5h31mins to 6h30mins & 11.2 & 10.9 & 11.6 \\
& 6h31mins to 7h30mins & 5.5 & 5.6 & 8.4 \\
& 7h31mins to 8h30mins & 9.0 & 9.1 & 6.7 \\
& More than 8h30mins & 14.2 & 13.7 & 11.3 \\
\hline Vigorous physical & Less than 30mins & 4.5 & 4.7 & 12.9 \\
activity per day & 31mins to 60mins & 15.6 & 11.9 & 22.5 \\
& 61mins to 90mins & 4.9 & 5.0 & 11.8 \\
& 91mins to 120mins & 10.3 & 9.7 & 4.6 \\
& More than 120mins & 3.7 & 20.2 & 7.4 \\
& Never do vigorous physical activity & 61.0 & 48.4 & 40.8 \\
\hline Moderate physical & Less than 30mins & 11.4 & 8.5 & 18.1 \\
activity per day & 31mins to 60mins & 20.9 & 15.1 & 25.5 \\
& 61mins to 90mins & 4.7 & 4.9 & 11.8 \\
& 91mins to 120mins & 13.2 & 11.7 & 4.4 \\
& More than 120mins & 3.9 & 21.7 & 7.1 \\
& Never do moderate physical activity & 46.0 & 38.1 & 33.3 \\
\hline Walking per day & Less than 30mins & 41.7 & 34.5 & 39.5 \\
& 31mins to 60mins & 24.2 & 22.8 & 32.3 \\
& 61mins to 90mins & 6.5 & 10.2 \\
& 91mins to 120mins & 8.2 & 3.7 \\
& More than 120mins & 8.3 & 5.5 \\
& Never walk for more than 10 minutes & 1.8 & 11.6 & 8.9 \\
\hline
\end{tabular}


Supplemental Table 2: Summary statistics for sitting time (minutes) in Eurobarometer 58.2, 64.3 and 80.2 by year and country (weighted data)

\begin{tabular}{|c|c|c|c|c|}
\hline Country & Statistic & 2002 & 2005 & 2013 \\
\hline \multirow[t]{3}{*}{ France } & $\mathrm{N}$ & 988 & 976 & 1011 \\
\hline & Mean (SD) & $292.2(266.4)$ & $286.7(301.8)$ & $292.6(260.3)$ \\
\hline & $50 \%$ Quartile [25\%, 75\%] & $240[180,390]$ & $240[180,360]$ & $300.5[180.5,420.5]$ \\
\hline \multirow[t]{3}{*}{ Belgium } & $\mathrm{N}$ & 1016 & 992 & 1072 \\
\hline & Mean (SD) & $320.9(119.8)$ & $343.4(143.2)$ & $300.7(109.3)$ \\
\hline & $50 \%$ Quartile [25\%, 75\%] & $300[180,480]$ & $300[180,480]$ & $300.5[180.5,420.5]$ \\
\hline \multirow{3}{*}{ Netherlands } & $\mathrm{N}$ & 970 & 1011 & 1026 \\
\hline & Mean (SD) & $357.3(155.4)$ & $409.7(189.5)$ & $376.1(123.1)$ \\
\hline & $50 \%$ Quartile [25\%, 75\%] & $300[240,480]$ & $360[240,540]$ & $360.5[300.5,540]$ \\
\hline \multirow[t]{3}{*}{ West Germany } & $\mathrm{N}$ & 917 & 894 & 1010 \\
\hline & Mean (SD) & $337.3(315.3)$ & $337.1(312.7)$ & $297.5(256.9)$ \\
\hline & $50 \%$ Quartile [25\%, 75\%] & $300[180,480]$ & $300[181,465]$ & $300.5[180.5,420.5]$ \\
\hline \multirow[t]{3}{*}{ Italy } & $\mathrm{N}$ & 974 & 960 & 965 \\
\hline & Mean (SD) & $334.7(266)$ & 267.7 (302) & 266.7 (253.3) \\
\hline & $50 \%$ Quartile [25\%, $75 \%]$ & $300[180,480]$ & $240[120,360]$ & $240.5[180.5,360.5]$ \\
\hline \multirow[t]{3}{*}{ Luxembourg } & $\mathrm{N}$ & 564 & 492 & 504 \\
\hline & Mean (SD) & $332.7(32.4)$ & $323.7(42.9)$ & $322.1(36.5)$ \\
\hline & $50 \%$ Quartile [25\%, $75 \%]$ & $300[180,480]$ & $300[180,480]$ & $300.5[180.5,480.5]$ \\
\hline \multirow[t]{3}{*}{ Denmark } & $\mathrm{N}$ & 955 & 977 & 1002 \\
\hline & Mean (SD) & $392(87.2)$ & $387.2(103.6)$ & $368.5(75.6)$ \\
\hline & $50 \%$ Quartile [25\%, $75 \%]$ & $360[240,480]$ & $360[240,490]$ & $360.5[240.5,480.5]$ \\
\hline \multirow[t]{3}{*}{ Ireland } & $\mathrm{N}$ & 985 & 894 & 981 \\
\hline & Mean (SD) & $286.4(65)$ & $290.8(74.5)$ & $266.8(64.9)$ \\
\hline & $50 \%$ Quartile [25\%, $75 \%]$ & $240[180,360]$ & $240[180,360]$ & $240.5[180.5,360.5]$ \\
\hline \multirow[t]{3}{*}{ Great Britain } & $\mathrm{N}$ & 980 & 900 & 982 \\
\hline & Mean (SD) & $294.7(278.6)$ & $324.5(339.6)$ & $299.8(261.9)$ \\
\hline & $50 \%$ Quartile [25\%, $75 \%]$ & $240[180,360]$ & $300[180,420]$ & $300.5[180.5,420.5]$ \\
\hline \multirow{3}{*}{$\begin{array}{l}\text { Northern } \\
\text { Ireland }\end{array}$} & $\mathrm{N}$ & 285 & 286 & 320 \\
\hline & Mean (SD) & $301(84.1)$ & $299.2(90.2)$ & $278.6(82.6)$ \\
\hline & $50 \%$ Quartile [25\%, $75 \%]$ & $240[180,420]$ & $240[180,360]$ & $240.5[180.5,420.5]$ \\
\hline \multirow[t]{3}{*}{ Greece } & $\mathrm{N}$ & 984 & 996 & 1005 \\
\hline & Mean (SD) & $309.6(123.7)$ & $370.8(124.9)$ & $304.7(108.4)$ \\
\hline & $50 \%$ Quartile [25\%, $75 \%]$ & $300[180,420]$ & $360[240,480]$ & $300.5[180.5,420.5]$ \\
\hline \multirow[t]{3}{*}{ Spain } & $\mathrm{N}$ & 936 & 949 & 1005 \\
\hline & Mean (SD) & $295.6(221.2)$ & $281.4(244.7)$ & 265 (201.9) \\
\hline & $50 \%$ Quartile [25\%, 75\%] & $240[180,385]$ & $244[179,366]$ & $240.5[180.5,360.5]$ \\
\hline \multirow[t]{3}{*}{ Portugal } & $\mathrm{N}$ & 951 & 1000 & 996 \\
\hline & Mean (SD) & $234.1(97.4)$ & $198.4(119.6)$ & $230.9(106.1)$ \\
\hline & $50 \%$ Quartile [25\%, 75\%] & $180[120,300]$ & $180[60,300]$ & $180.5[120.5,360.5]$ \\
\hline \multirow[t]{3}{*}{ East Germany } & $\mathrm{N}$ & 913 & 530 & 555 \\
\hline & Mean (SD) & $339.9(140.1)$ & $313.6(202.9)$ & $284.4(182.7)$ \\
\hline & $50 \%$ Quartile [25\%, 75\%] & $300[180,480]$ & $300[180,420]$ & $240.5[180.5,360.5]$ \\
\hline \multirow[t]{3}{*}{ Finland } & $\mathrm{N}$ & 994 & 979 & 958 \\
\hline & Mean (SD) & $362(87.8)$ & $345.9(109.8)$ & $339.4(74.9)$ \\
\hline & $50 \%$ Quartile [25\%, $75 \%]$ & $330[210,480]$ & $300[180,480]$ & $360.5[240.5,420.5]$ \\
\hline \multirow[t]{3}{*}{ Sweden } & $\mathrm{N}$ & 957 & 1030 & 993 \\
\hline & Mean (SD) & $355(110.4)$ & $343.2(120.3)$ & $356.7(97.2)$ \\
\hline & $50 \%$ Quartile $[25 \%, 75 \%]$ & $300[240,480]$ & $300[180,480]$ & $360.5[240.5,480.5]$ \\
\hline \multirow[t]{3}{*}{ Austria } & $\mathrm{N}$ & 878 & 1002 & 961 \\
\hline & Mean (SD) & $305.6(106.2)$ & $302.9(108.4)$ & $329.2(85.7)$ \\
\hline & $50 \%$ Quartile $[25 \%, 75 \%]$ & $270[180,420]$ & $300[180,400]$ & $300.5[240.5,420.5]$ \\
\hline \multirow[t]{2}{*}{ Cyprus } & $\mathrm{N}$ & & 467 & 498 \\
\hline & Mean (SD) & & $367.7(52.6)$ & $298.2(44.5)$ \\
\hline
\end{tabular}




\begin{tabular}{|c|c|c|c|}
\hline & $50 \%$ Quartile [25\%, 75\%] & $360[210,480]$ & $300.5[180.5,420.5]$ \\
\hline \multirow{3}{*}{$\begin{array}{r}\text { Czech } \\
\text { Republic }\end{array}$} & 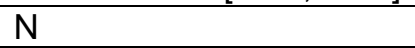 & 943 & 1005 \\
\hline & Mean (SD) & $386(144.1)$ & $326.9(115.3)$ \\
\hline & $50 \%$ Quartile [25\%, 75\%] & $360[240,540]$ & $300.5[240.5,480.5]$ \\
\hline \multirow[t]{3}{*}{ Estonia } & $\mathrm{N}$ & 950 & 1002 \\
\hline & Mean (SD) & $335.4(43.1)$ & $313.6(36.9)$ \\
\hline & $50 \%$ Quartile [25\%, 75\%] & $300[180,480]$ & $300.5[180.5,420.5]$ \\
\hline \multirow[t]{3}{*}{ Hungary } & $\mathrm{N}$ & 969 & 989 \\
\hline & Mean (SD) & $271.1(127.8)$ & $252.6(103.8)$ \\
\hline & $50 \%$ Quartile [25\%, 75\%] & $240[150,360]$ & $240.5[120.5,360.5]$ \\
\hline \multirow[t]{3}{*}{ Latvia } & $\mathrm{N}$ & 1000 & 996 \\
\hline & Mean (SD) & $273.2(56.7)$ & $290.1(44.4)$ \\
\hline & $50 \%$ Quartile [25\%, 75\%] & $240[120,420]$ & $300.5[180.5,420.5]$ \\
\hline \multirow[t]{3}{*}{ Lithuania } & $\mathrm{N}$ & 872 & 1006 \\
\hline & Mean (SD) & $265.7(81.6)$ & $298.1(60.2)$ \\
\hline & $50 \%$ Quartile [25\%, 75\%] & $240[120,360]$ & $300.5[180.5,420.5]$ \\
\hline \multirow[t]{3}{*}{ Malta } & $\mathrm{N}$ & 444 & 492 \\
\hline & Mean (SD) & $250.9(37.1)$ & $253.7(32.9)$ \\
\hline & $50 \%$ Quartile [25\%, 75\%] & $240[120,360]$ & $240.5[120.5,360.5]$ \\
\hline \multirow[t]{3}{*}{ Poland } & $\mathrm{N}$ & 964 & 892 \\
\hline & Mean (SD) & $335(272.5)$ & $279.5(221.7)$ \\
\hline & $50 \%$ Quartile [25\%, 75\%] & $300[180,480]$ & $240.5[180.5,420.5]$ \\
\hline \multirow[t]{3}{*}{ Slovakia } & $\mathrm{N}$ & 982 & 976 \\
\hline & Mean (SD) & $321.3(89.9)$ & $311.7(81.9)$ \\
\hline & $50 \%$ Quartile [25\%, 75\%] & $300[180,420]$ & $300.5[180.5,420.5]$ \\
\hline \multirow[t]{3}{*}{ Slovenia } & $\mathrm{N}$ & 1005 & 1111 \\
\hline & Mean (SD) & $309.1(59.8)$ & $249(47.3)$ \\
\hline & $50 \%$ Quartile [25\%, 75\%] & $240[180,480]$ & $240.5[120.5,360.5]$ \\
\hline
\end{tabular}

*Since sitting time was collected as a categorical variable in 2013, all sitting time statistics are estimated 
Supplemental Table 3: Odds Ratios $( \pm 95 \% \mathrm{Cl})$ from a series of logistic regressions modelling the probability of being in the highest sitting category by country (values displayed in Figures 3 and 4)

\begin{tabular}{|c|c|c|c|c|c|c|}
\hline & Year & $\begin{array}{r}\text { Year } \\
\text { Compared }\end{array}$ & Country & $\begin{array}{r}\text { Lower } 95 \% \\
\mathrm{Cl}\end{array}$ & OR & $\begin{array}{r}\text { Upper 95\% } \\
\mathrm{Cl}\end{array}$ \\
\hline \multirow[t]{18}{*}{2013} & & 2002 & Austria & 0.77 & 1.01 & 1.31 \\
\hline & & & Sweden & 0.74 & 0.95 & 1.22 \\
\hline & & & Finland & 0.65 & 0.85 & 1.10 \\
\hline & & & East Germany & 0.35 & 0.49 & 0.68 \\
\hline & & & Portugal & 0.47 & 0.64 & 0.88 \\
\hline & & & Spain & 0.31 & 0.43 & 0.58 \\
\hline & & & Greece & 0.60 & 0.77 & 0.99 \\
\hline & & & Northern Ireland & 0.62 & 1.00 & 1.60 \\
\hline & & & Great Britain & 0.75 & 0.97 & 1.25 \\
\hline & & & Ireland & 0.46 & 0.65 & 0.90 \\
\hline & & & Denmark & 0.60 & 0.76 & 0.95 \\
\hline & & & Luxembourg & 0.57 & 0.80 & 1.13 \\
\hline & & & Italy & 0.24 & 0.32 & 0.43 \\
\hline & & & West Germany & 0.55 & 0.71 & 0.91 \\
\hline & & & Netherlands & 0.92 & 1.18 & 1.51 \\
\hline & & & Belgium & 0.46 & 0.59 & 0.75 \\
\hline & & & France & 0.80 & 1.03 & 1.33 \\
\hline & & & Overall & 0.63 & 0.69 & 0.76 \\
\hline \multirow[t]{18}{*}{2005} & & 2002 & Austria & 0.59 & 0.77 & 1.00 \\
\hline & & & Sweden & 0.65 & 0.82 & 1.03 \\
\hline & & & Finland & 0.72 & 0.92 & 1.17 \\
\hline & & & East Germany & 0.53 & 0.72 & 0.98 \\
\hline & & & Portugal & 0.56 & 0.78 & 1.10 \\
\hline & & & Spain & 0.56 & 0.75 & 0.99 \\
\hline & & & Greece & 1.68 & 2.13 & 2.69 \\
\hline & & & Northern Ireland & 0.49 & 0.79 & 1.27 \\
\hline & & & Great Britain & 0.91 & 1.17 & 1.51 \\
\hline & & & Ireland & 0.64 & 0.86 & 1.15 \\
\hline & & & Denmark & 0.63 & 0.79 & 1.00 \\
\hline & & & Luxembourg & 0.56 & 0.81 & 1.17 \\
\hline & & & Italy & 0.32 & 0.43 & 0.56 \\
\hline & & & West Germany & 0.72 & 0.92 & 1.17 \\
\hline & & & Netherlands & 1.66 & 2.10 & 2.67 \\
\hline & & & Belgium & 0.83 & 1.04 & 1.31 \\
\hline & & & France & 0.63 & 0.82 & 1.07 \\
\hline & & & Overall & 0.80 & 0.87 & 0.95 \\
\hline \multirow[t]{15}{*}{2013} & & 2005 & Slovenia & 0.33 & 0.43 & 0.57 \\
\hline & & & Slovakia & 0.64 & 0.82 & 1.07 \\
\hline & & & Poland & 0.38 & 0.49 & 0.63 \\
\hline & & & Malta & 0.78 & 1.29 & 2.12 \\
\hline & & & Lithuania & 0.59 & 0.78 & 1.03 \\
\hline & & & Latvia & 0.75 & 0.98 & 1.27 \\
\hline & & & Hungary & 0.47 & 0.63 & 0.84 \\
\hline & & & Estonia & 0.67 & 0.85 & 1.08 \\
\hline & & & Czech Republic & 0.47 & 0.59 & 0.73 \\
\hline & & & Cyprus & 0.33 & 0.46 & 0.66 \\
\hline & & & Austria & 1.07 & 1.39 & 1.81 \\
\hline & & & Sweden & 0.96 & 1.23 & 1.56 \\
\hline & & & Finland & 0.76 & 0.98 & 1.27 \\
\hline & & & East Germany & 0.50 & 0.74 & 1.08 \\
\hline & & & Portugal & 0.64 & 0.90 & 1.26 \\
\hline
\end{tabular}




\begin{tabular}{lllll}
\hline & Spain & 0.46 & 0.64 & 0.88 \\
\cline { 2 - 5 } & Greece & 0.32 & 0.40 & 0.51 \\
\cline { 2 - 5 } & Northern Ireland & 0.84 & 1.35 & 2.17 \\
\cline { 2 - 5 } & Great Britain & 0.70 & 0.89 & 1.15 \\
\cline { 2 - 5 } & Ireland & 0.57 & 0.80 & 1.12 \\
\cline { 2 - 5 } & Denmark & 0.81 & 1.02 & 1.29 \\
\cline { 2 - 5 } & Luxembourg & 0.71 & 1.04 & 1.53 \\
\cline { 2 - 5 } & Italy & 0.58 & 0.81 & 1.11 \\
\cline { 2 - 5 } & West Germany & 0.64 & 0.83 & 1.07 \\
\cline { 2 - 5 } & Netherlands & 0.50 & 0.62 & 0.77 \\
\cline { 2 - 5 } & Belgium & 0.47 & 0.39 & 0.76 \\
\cline { 2 - 5 } & France & 1.04 & $\mathbf{0 . 7 9}$ & $\mathbf{0 . 8 6}$ \\
\cline { 2 - 5 } & Overall & $\mathbf{0 . 7 3}$ & & \\
\hline
\end{tabular}

Italics $=95 \% \mathrm{Cl}$ does not span 1.0 
Supplemental Figure 1: Weighted frequency distributions for sitting time category for each country/region with data in all three time points

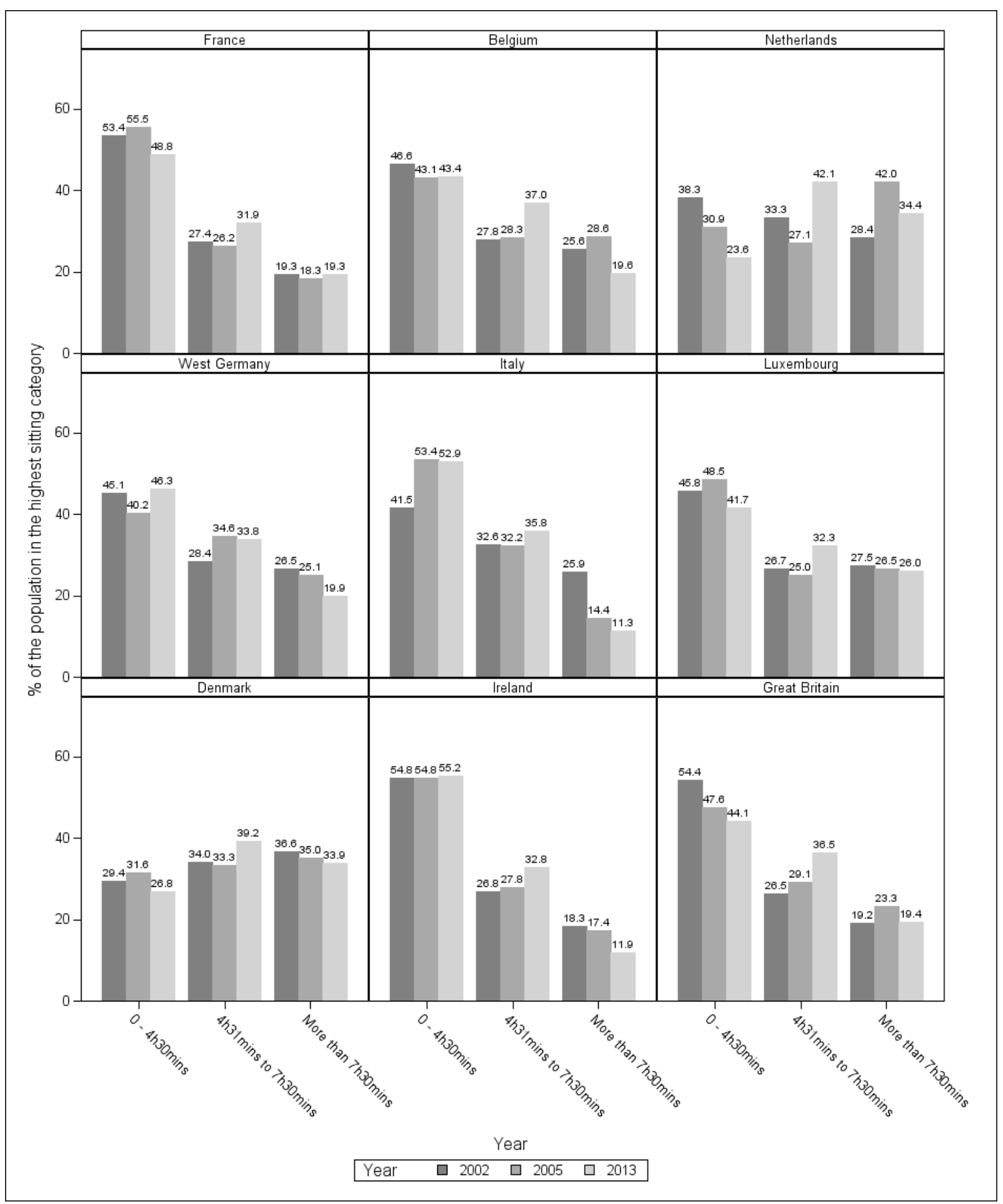




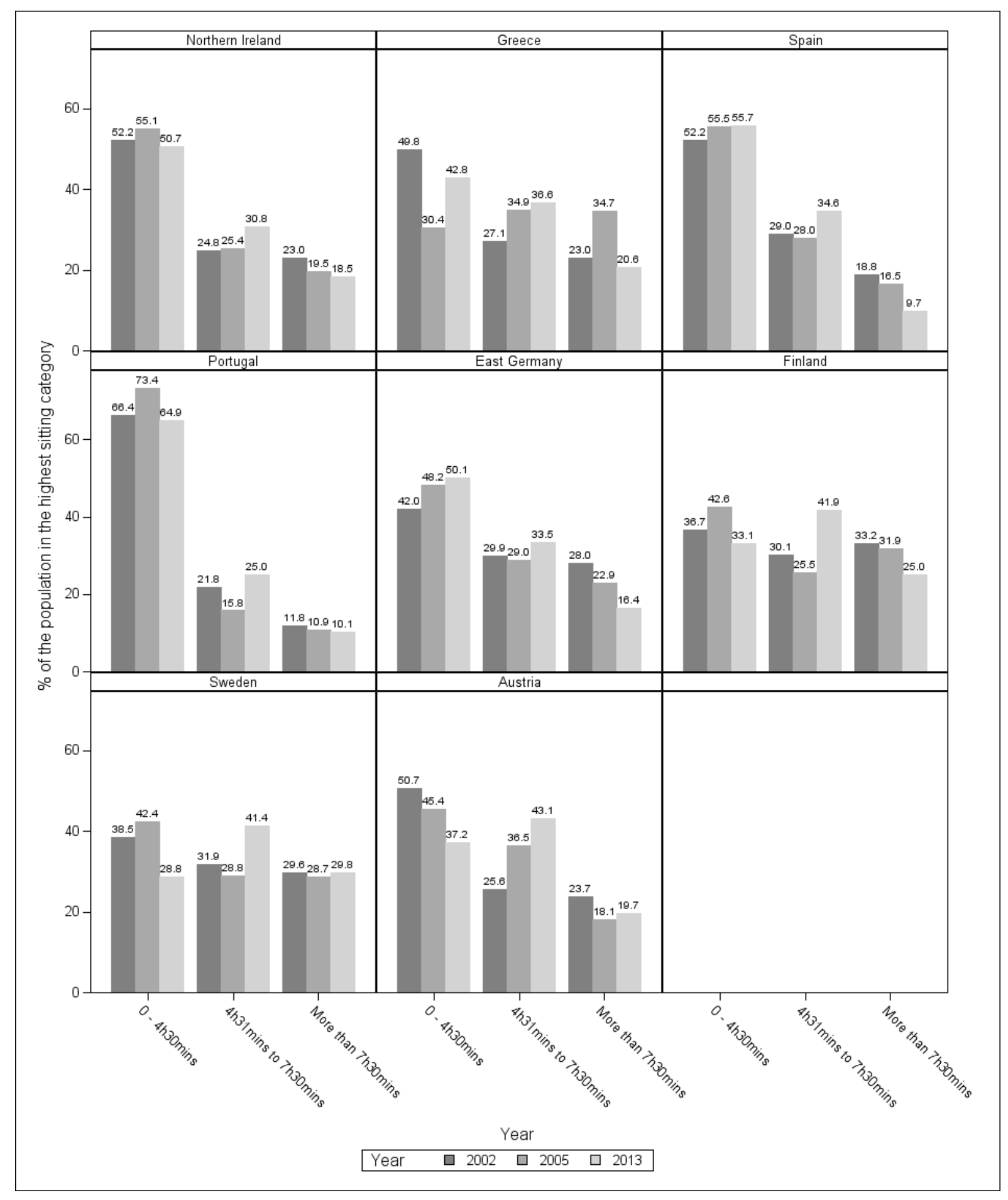


Supplemental Figure 2: Weighted frequency distributions for sitting time category for the pooled sample of 10 countries/regions with data in 2005 and $2013\left(N_{\text {sum of weights }}=18320\right)$

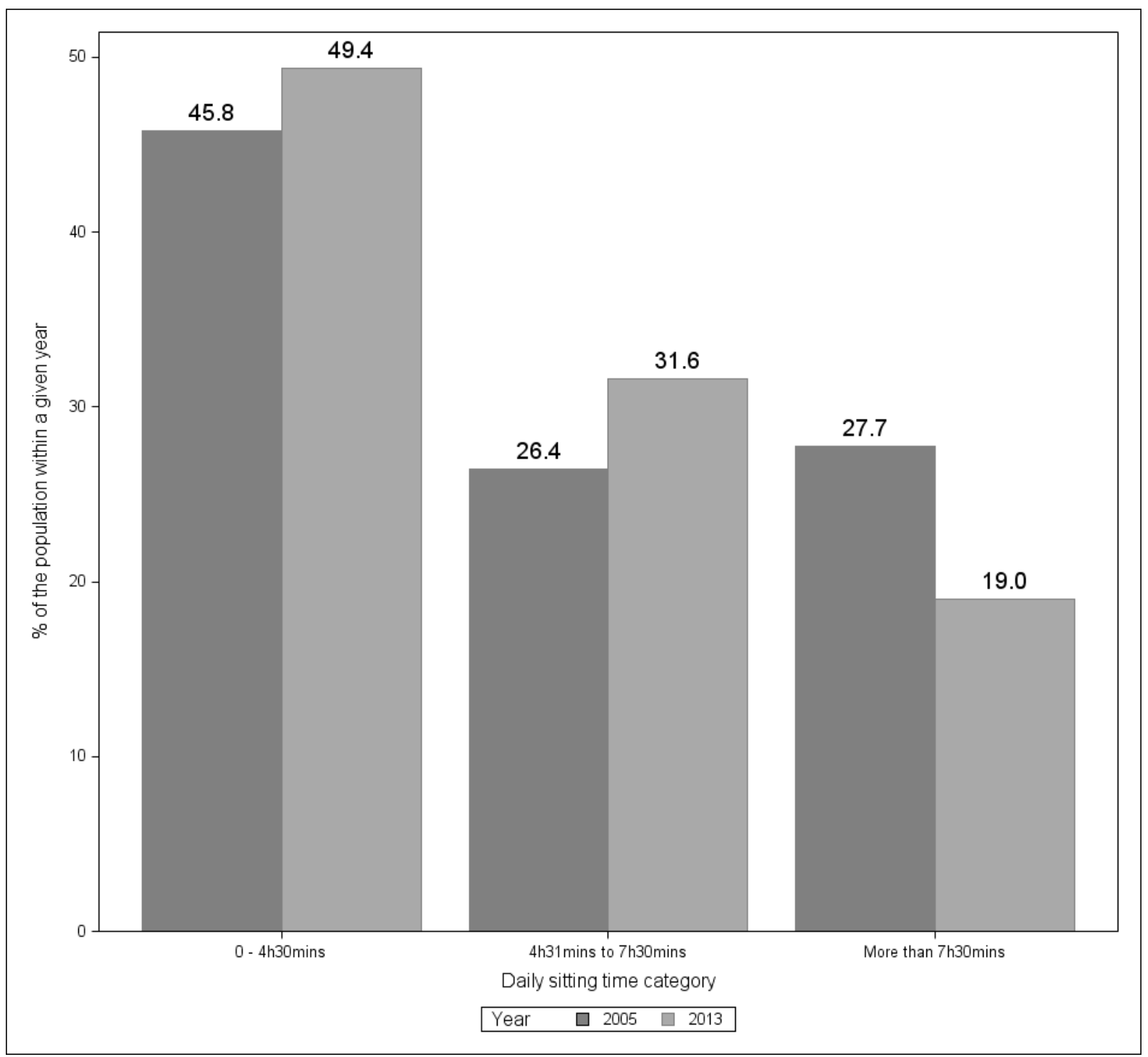


Supplemental Figure 3: Weighted frequency distributions for sitting time category for each of the 10 countries/regions with data in 2005 and 2013

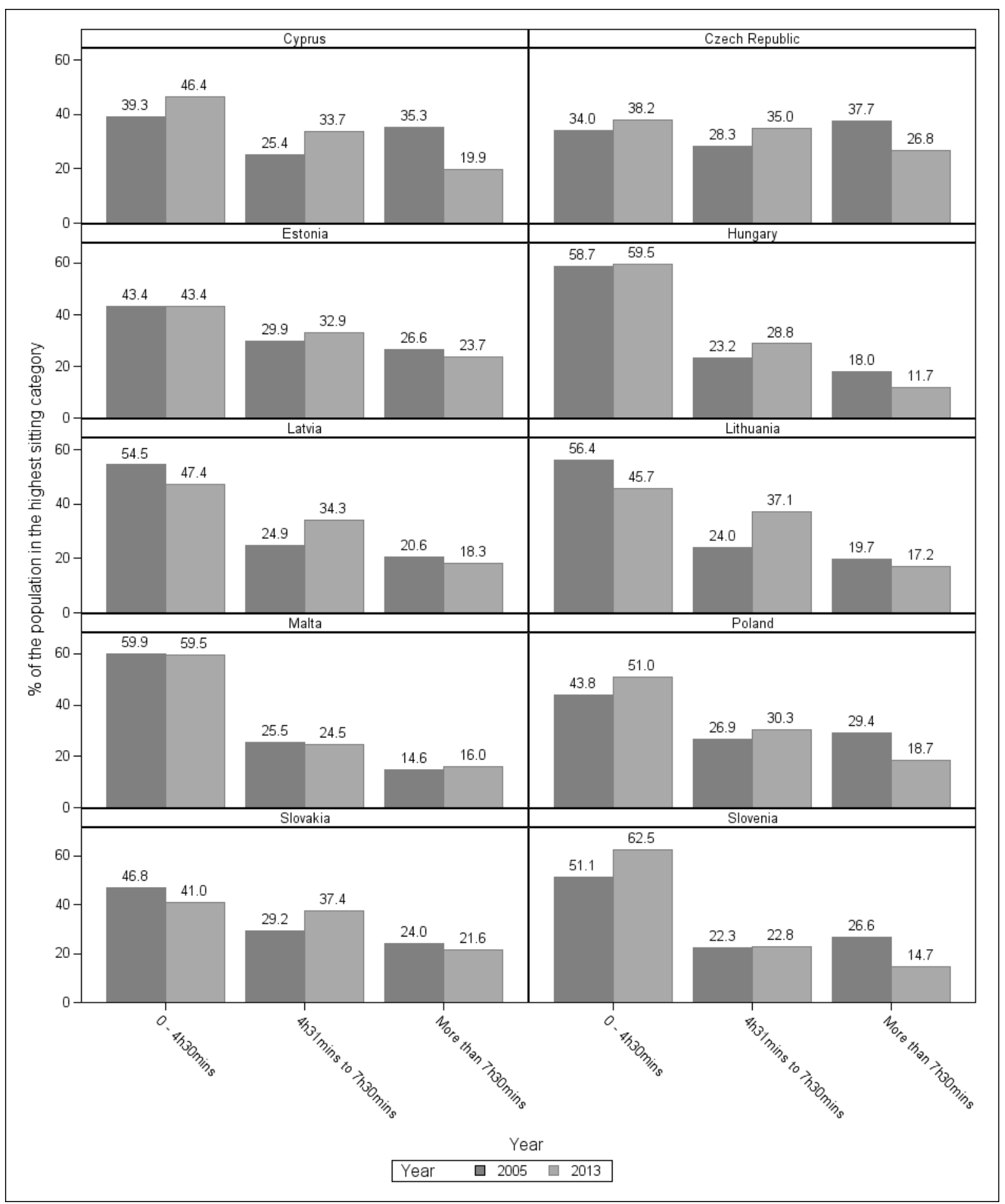


Supplemental Figure 4: Weighted frequency distributions for sitting time category in 2005 and 2013 for the pooled sample of 27 countries/regions $\left(N_{\text {sum of weights }}=49559\right)$

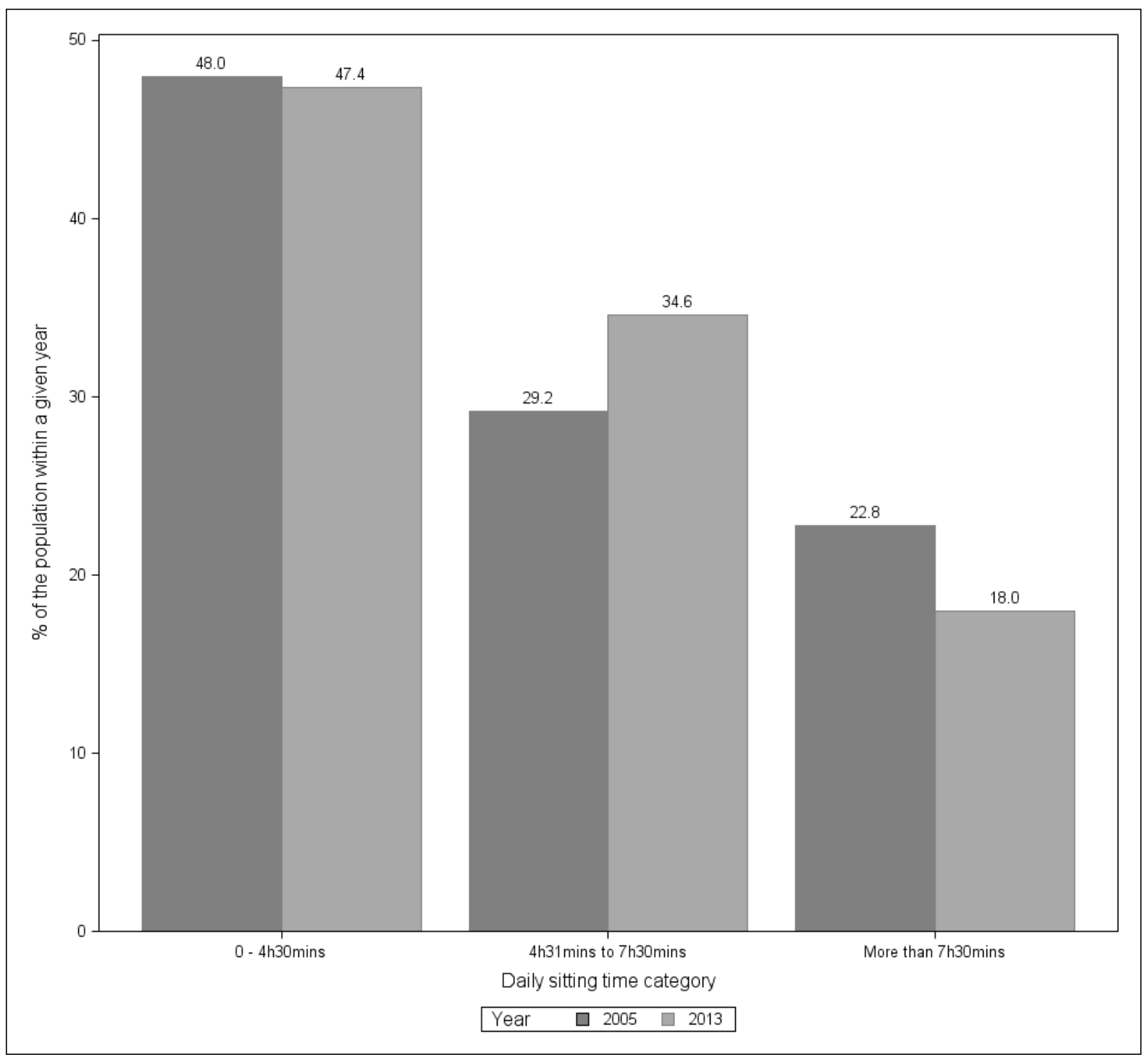

